\section{A dor crônica sob o olhar médico: modelo biomédico e prática clínica}

\author{
The medical perspective towards chronic pain: \\ biomedical model and clinical practice
}

\footnotetext{
1 Faculdade de Medicina, Universidade Federal da Bahia, Salvador, Brasil. 2 Instituto de Saúde Coletiva, Universidade Federal da Bahia, Salvador, Brasil.

Correspondência

M. A. G. Lima

Departamento de Medicina Preventiva, Faculdade de Medicina, Universidade

Federal da Bahia.

Av. Reitor Miguel Calmon $s / n$.

Salvador, $B A$

40110-100, Brasil

angelim@ufba.br
}

\begin{abstract}
This study aimed to shed light on the meanings ascribed to chronic pain in medical discourse and clinical practice in two Pain Clinics located in University hospitals in Salvador (Bahia) and São Paulo, Brazil. An ethnographic approach used participant observation and semi-structuralized interviews with attending and managing physicians. Data analysis drew on the clinical models developed by Byron Good and the medical rationalities project formulated by Madel Luz. The meanings emerging from the study were the recognition of chronic pain by biomedicine as a disease rather than a symptom, its invisibility to physicians, and its non-communicability and inevitability. The informants suggested the need for valorization of the human encounter in the clinic, exercise of understanding as opposed to suspicion, and negotiation of sustainable therapeutic projects.
\end{abstract}

Pain; Pain Clinics; Physician's Practice Patterns
Mônica Angelim Gomes de Lima 1

Leny A. Bomfim Trad 2

\section{Introdução}

A dor crônica é um importante problema de saúde pública contemporâneo 1,2, assim como a crescente demanda por serviços de saúde e recursos tecnológicos para a abordagem das diversas dimensões envolvidas na incapacidade e sofrimento resultantes ${ }^{3}$. Ao lado disso, lidar com o cuidado da pessoa com dor crônica tem representado um grande desafio para os profissionais de saúde ${ }^{4,5}$.

Nos últimos cinqüenta anos, o estudo da dor tem contribuído com mudanças profundas na compreensão da dinâmica e complexidade do sistema nervoso; tem impulsionado o reconhecimento da importância das dimensões sócioculturais e psíquicas na experiência e expressão do fenômeno doloroso, além de proporcionado a diversificação de recursos terapêuticos mobilizados no cuidado da dor crônica 7,8.

Um dos aspectos mais fascinantes da dor é a ambigüidade de sua presença entre o corpo e a mente. A dor é definida como sendo "uma experiência sensorial e emocional desagradável relacionada com o dano real ou potencial de algum tecido ou que se descreve em termos de tal dano" 9 (p. 11). Este conceito reflete mudanças nucleares na concepção da dor, absorve o visível e o invisível impostos pela dor, notadamente, a dor crônica.

Estudos etnográficos e teóricos, no campo da Antropologia Médica, têm explicitado as impli- 
cações práticas e morais sobre os doentes e suas famílias a partir da escolha sobre o tipo de explicação e prática clínica adotada no cuidado do doloroso crônico 10,11,12,13. Para Kirmayer 13, ao médico cabe, em seu cotidiano clínico, reconhecer a importância da dor em três perspectivas: como um elemento de orientação do diagnóstico e tratamento, como a base para a compreensão empática da experiência do doente e como um traço da significância moral das queixas e do sofrimento.

Neste artigo exploramos a prática através de seus praticantes no contexto da clínica, buscando compreender os sentidos e os significados atribuídos à dor crônica por médicos na Clínica de Dor. Partiu-se do pressuposto de que "tornarse terapeuta de dor" expõe este médico à experiência de lidar com situações limites, exigindo explorar habilidades não valorizadas na formação biomédica, revelando ligações da prática clínica com valores éticos e morais postos pela biomedicina 14 .

\section{Construindo a moldura teórico- metodológica}

\section{O lócus e os participantes}

Trata-se de um estudo etnográfico envolvendo duas clínicas de dor situadas em hospitais-escola, respectivamente em Salvador, Estado da Bahia (Clínica H) e São Paulo (Clínica M). Foram realizadas entrevistas em profundidade com dezesseis médicos e observação participante 15. Em Salvador a observação participante transcorreu durante dois anos (julho/2002-dezembro/2004), sendo este o lócus privilegiado deste projeto. Em São Paulo, o tempo de permanência foi de quarenta dias (maio-junho/2003) e contemplou o acompanhamento das principais atividades do grupo e entrevistas com os coordenadores dos serviços. Contou-se com o consentimento da direção técnica de ambas as instituições e aprovação nos respectivos Comitês de Ética.

A escolha destes locais foi respaldada pelas diferenças complementares existentes entre eles. O primeiro, a Clínica de Dor de Salvador, caracterizava-se, naquele momento, por ser um empreendimento relativamente recente (seis anos), embora com rápido crescimento e afirmação institucional. A Clínica de Dor de São Paulo foi incluída pela tradição e pioneirismo no tratamento da dor crônica, principal centro de referência para o tratamento e formação em dor no Brasil.

Foi entrevistado o mesmo número de médicos (oito) nas duas Clínicas. Em Salvador, foram entrevistados a totalidade de profissionais e alguns pacientes; em São Paulo, optou-se por entrevistar apenas os coordenadores dos diversos serviços oferecidos. Definiu-se o critério da saturação pela repetição, para estabelecer o momento do término das entrevistas.

\section{Apresentando o cenário: o grupo de dor e o hospital-escola}

A Clínica de Dor do Hospital das Clínicas de Salvador iniciou em 1998 e vem ampliando o quadro de profissionais em atividades de assistência, de ensino e pesquisa. São aproximadamente quarenta profissionais e estudantes com diversas formações em torno do núcleo inicial liderado por um anestesiologista e por uma psicóloga. Estes profissionais são, na sua maioria, voluntários, que dedicam um turno para o atendimento de pacientes não pagantes, encaminhados por serviços externos e internos do hospital. Oferece regularmente atendimento médico e de enfermagem, psicoterapia, fisioterapia convencional e não convencional: pilates, psicanálise, acupuntura além de odontologia, hipnose, musicoterapia e mais recentemente quiropraxia.

A Clínica de Dor tem se caracterizado por reunir terapeutas e práticas convencionais e nãoconvencionais, voltados para alcançar alguns objetivos comuns: fortalecer a compreensão da dor como crônica e incurável redirecionando os objetivos do "sujeito que sofre de dor" para aumentar o nível de atividade física, retorná-lo ao trabalho ou alguma atividade ocupacional, diminuir a procura de serviços de saúde em momentos de reagudização do quadro, reduzir questões jurídicas por indenizações e promover melhor relação custo-efetividade 16,17.

O formato dos programas de tratamento da dor crônica parte da abordagem biomédica com a priorização da medicação, seguida da psicoterapia e medicina física. Nestes centros identifica-se o predomínio de especialidades médicas, dentre elas a psiquiatria, anestesia, fisiatria, neurologia e ortopedia e outros profissionais de saúde como a odontologia, terapias corporais ativas, quiropraxia, terapias alimentares e fitoterapia 7.

As tarefas de olhar e escutar, que constituem as bases do trabalho etnográfico em campo ${ }^{18}$, tiveram como alvo privilegiado o modo como os clínicos constroem a dor como objeto médico. Buscou-se explorar, portanto, como os médicos da clínica de dor compreendem, explicam, organizam e intervêm na dor, enquanto objeto médico, cotejando aproximações e distanciamentos operados entre o modelo biomédico e o hermenêutico como propostos por Good \& Good 19.

A leitura dos relatos dos médicos e das observações da prática clínica foi feita a partir de 
quatro das características propostas por Good \& Good 19 para os modelos clínicos, o biomédico e o hermenêutico, quais sejam: entidade patológica, estratégia interpretativa, estrutura de relevância, objetivo interpretativo e objetivo terapêtico, associando-se dois elementos propostos para o estudo das racionalidades médicas: a fisiologia ou dinâmica vital humana e o sistema de intervenção terapêutico pela ênfase que este elemento tem no caso da proposta terapêutica da dor crônica na biomedicina 20 .

O lugar da primeira autora deste artigo (M. A. G. L.), como médica e estudiosa do tema, é parte do horizonte interpretativo, seja na compreensão dos dilemas vividos pelos médicos clínicos, seja na familiaridade com os sentidos circulantes sobre a dor, o sofredor e a técnica, seja ainda no propósito de reconhecer e organizar recursos para o cuidado dos sujeitos que sofrem de dor.

\section{O que é dor crônica? - Definindo contornos, reconhecendo uma entidade}

Para os médicos ouvidos, a dor crônica é claramente entendida como uma entidade nosológica específica. $\mathrm{O}$ que a torna singular é a relação de retro-alimentação que a dor tem sobre si mesma. Como afirmam Melzack \& Wall 6 (p. 204) "um círculo vicioso entre os sistemas centrais e periféricos que mantêm a atividade patológica da medula". Este mecanismo afeta uma infinidade de elementos que postos em movimento autonomizam-se e passam a produzir dor onde antes poderia ser prazer, portanto, dor crônica é "distorção, ela é uma deturpação de um processo que deveria ter sido agudo" (Márcio, anestesista, Clínica M).

A idéia de doença passa por admitir implicitamente mudanças no corpo e na mente, na bioquímica, na genética, na psique, no comportamento. Estes médicos afirmam: "é um agente transformador, você passa a ser um novo indivíduo depois da dor" (Aline, anestesista, Clínica $\mathrm{H}$ ); "altera a carga genética, então lhe dá uma expressão fenotípica que é diferente da anterior" (Arthur, anestesista, Clínica H); "dor crônica é uma outra entidade totalmente diferente" (Mário, anestesista, Clínica H); "é excesso de uma tentativa inicial de proteção, excesso de resposta” (Arthur, anestesista, Clínica $\mathrm{H})$.

Um jovem médico anestesista e estagiário recém chegado na Clínica de Dor descreve a dor e o sistema nervoso central como uma dinâmica antes não conhecida. Para ele, “dor crônica é uma deturpação, um processo que deveria ter sido agudo; existem alguns processos que ocorrem de uma maneira patológica. O sistema nervoso central ao contrário do que eu imaginava é extremamente dinâmico, ele começa a aumentar a área de representação daquela região, da medula e do córtex, altera os receptores para tato e pressão que começam a disparar e, então, qualquer estímulo vira dor" (Márcio, estagiário, Clínica M).

A dor não é um objeto de estudo valorizado no curso médico, apesar de onipresente na prática clínica. Está fortemente associada à idéia de lesão, de proteção e, portanto, um sintoma, na perspectiva foucaultiana, um ato de descrição que revela uma realidade subjacente, a lesão, a ser buscada, diagnosticada, tratada e curada. A dor crônica é apresentada, portanto, como um "erro de leitura", uma alteração deste sistema de proteção, que passa a ter um sentido ambíguo entre proteção e perversão.

Este entendimento da dor descortina questões nucleares para a biomedicina, pois, atinge frontalmente cânones desta racionalidade médica quais sejam: a constituição do "olhar médico" 21 e a diferenciação entre o normal e o patológico 22. Este tema é explorado em outro artigo da autora desta pesquisa 23. Concordando com Kleinman et al. 8, a dor crônica representa um caso especial na nosologia biomédica atual, é diferente das desordens biomédicas crônicas de um modo geral, como a diabetes ou a hipertensão, e das doenças psiquiátricas reconhecidas, como a depressão. A dor crônica é usada como uma categoria não oficial, uma categoria anômala, parcialmente legitimada como doença. $\mathrm{Na}$ ausência de mecanismos fisiológicos conhecidos, a atenção tem sido voltada para determinantes psicológicos e sociais da dor.

\section{A invisibilidade da dor e a visibilidade da prática clínica - estratégias interpretativas}

A dor não só é invisível, mas imponderável e incomensurável. Diagnosticar, manejar o processo terapêutico e acompanhar o resultado tornam-se tarefas totalmente dependentes do outro. O relato abaixo expressa a dificuldade de um médico recém-formado de lidar com um objeto que não se vê e apóia-se basicamente em uma imagem subjetiva.

"Você é completamente dependente de uma queixa subjetiva de um sujeito (...) não existe nenhum exame que me prove que dói tanto. No entanto quando ele volta na outra consulta ele diz: 'doutor doía dez, mas agora é cinco'. Quer dizer, você tratou um negócio que você não palpa, não vê, não sente, não examina, uma coisa assim extremamente subjetiva..." (Márcio, estagiário, Clínica $\mathrm{M})$. 
Reduzir a invisibilidade da dor passa pela localização, espacialização no corpo do lugar da dor. O "olhar médico" 21 , como descrito por Foucault, mantém-se como o principal recurso mobilizado para a visualização da dor. Quando esta espacialização mostra-se insuficiente para explicar a dor, o clínico depara-se com a dúvida e surge a referência ao psicológico.

"Primeiro tem que localizar essa dor, você pode topografar essa dor? O que tem aí que poderia doer? Músculo? Pulmão, não é. É preciso pensar uma só causa" (Eva, neurologista, Clínica $\mathrm{H}$ ).

A referência ao psicológico no processo terapêutico é reiterada como um componente fundamental da dor crônica. No atendimento clínico alguns elementos contribuem para lembrar este aspecto, geralmente alguma menção a traumas emocionais, dificuldades relacionais na família, na própria relação médico-paciente ou simplesmente porque o doente foge a um padrão de comportamento esperado.

Esta referência ao psicológico tem que ser feita com cuidado. A suspeição sobre a verdade da dor ou a sua atribuição a fatores psicológicos, em detrimento do reconhecimento do sofrimento físico, poderá ser uma causa de abandono do tratamento. Por outro lado, esta é uma ambigüidade presente para os médicos. O limite entre um e outro é impossível de ser traçado e a ênfase dada "depende da porta que ele entra e de onde o fulano faz a queixa”, como menciona Lauro, psiquiatra da Clínica M. Para os clínicos de dor, o componente psicológico não produz a dor, compõe o quadro, modula sua expressão e o apoio psicológico vai contribuir para a "reprogramação" desse sujeito. A idéia de reprogramação física e psíquica é central no tratamento da dor crônica, embora também aqui seja preciso assumir os limites.

“Toda dor tem um componente psicológico (...) o componente psicológico vai modular isto àquele momento da sua vida e você vai mostrar isto para o mundo através de um comportamento, seja verbal, seja postural, seja fisiológico (...) eu explico para o paciente assim: o senhor tem um Pentium, o seu Pentium virou dois oito meia e não vai rodar o programa do windows noventa e oito, então tem que voltar a ser Pentium. O senhor vai fazer o tratamento, o apoio psicológico, tudo isso é necessário, mas só vai reprogramar, se a máquina aceitar a programação" (Sérgio, fisiatra, Clínica M).

\section{Dor crônica é um agente transformador: estrutura de relevância}

A transformação que a dor opera no sujeito que sofre é esperada enquanto parte da doença e como um norteador da terapêutica. Novamente a teoria neurofisiológica oferece explicações para este fato percebido na clínica, através do reconhecimento da neuroplasticidade, admitindo mudanças estruturais do sistema nervoso central decorrentes da dor. As variações que se apresentam no sujeito com dor provocam o estranhamento da família, dos amigos e do próprio terapeuta. Sobretudo, exigem deste último, maleabilidade e atenção.

A perda da margem de manobra para lidar com os fatos da vida cotidiana e o isolamento são elementos que surgem ao descreverem uma pessoa com dor crônica. Estes terapeutas seguem buscando "pistas", "pequenas conquistas". Reconhecendo seus limites, eles vêm aprendendo a lidar com este novo sujeito, assumindo, aos poucos, a centralidade do doente para a viabilização de um projeto terapêutico.

"A pessoa que está diante de você não é mais a mesma pessoa, é outra pessoa, porque a dor altera a sua carga genética, então lhe dá uma expressão fenotípica que é diferente da anterior, da original. Então, a realidade que está diante de você não é a que lhe parece. (...) A gente que trabalha em Clínica de Dor tem que ir atrás dessas pistas" (Arthur, anestesista, Clínica $\mathrm{H}$ ).

Os médicos apontam como estruturas de relevância do doloroso crônico a dimensão que a dor ocupa na sua vida: o quanto o incapacita ou passa a ser o foco principal sobre o qual tudo gira. A forma de reagir, o comportamento do sujeito com dor crônica e o modo como se organiza em torno da dor é descrito de diferentes formas pelos médicos: "o que mais caracteriza esses pacientes é que eles têm uma alteração da psique, alteração emocional, alteração do comportamento, é como uma corda esticada, ele não tem muita margem de manobra do ponto de vista emocional" (Mário, anestesista, Clínica $\mathrm{H}$ ).

O êxito ou fracasso do tratamento tem por referência esta adaptabilidade à dor, que passa a ser um objetivo terapêutico importante. Como afirma Jackson 12, este é o discurso que orienta o tratamento da dor - "aprender a viver com dor" - um modelo de conversão positiva.

\section{Dor é dor, Dr. - a construção clínica da dor - procedimentos elucidatórios}

“Como é sua dor?”. Esta talvez seja a pergunta mais difícil de ser respondida pelo doente durante a consulta, são inúmeras as tentativas para respondê-la - "É dor, Dr.; dói aqui [tenta localizar com a mão]; dói tudo; dor é dor". Quando o médico insiste no "Como?", invariavelmente há um silêncio, como se o doente buscasse em sua 
memória palavras para descrevê-la e não raro há um pedido de esclarecimento "Como assim?". Descrevê-la é difícil. Para alguns, impossível. Em vários estudos este elemento aparece revelando a singularidade deste fenômeno que se constitui ao desconstruir o mundo-da-vida do doente, a dor pertence ao horizonte pré-lingüístico, anterior à linguagem 24 .

São recorrentes na Clínica de Dor as descrições feitas por Good 25, o estranhamento do corpo que passa "a agir" por conta própria e contra o self, a personificação de um mal que tortura a pessoa, impedindo-a de projetar-se no futuro, aprisionando-a a um presente contínuo. No entanto, para o médico, é necessária alguma aproximação desta dor, uma orientação que o guie em seu diagnóstico e nas decisões sobre a terapêutica. Algo que elucide a sua origem, quando possível, ou pelo menos seus contornos. A dor crônica talvez seja uma exemplificação limite do objeto da clínica que Clavreu 26 (p. 48) chama de um objeto-semblante, remetendo " a uma idéia de silhueta, onde os contrastes externos são mais relevantes que o detalhamento das figuras".

No dia-a-dia, os médicos perguntam sobre a intensidade da dor e suas variações, quando está melhor e quando está pior. Buscam as oscilações, os recursos terapêuticos utilizados e o que contribuiu para melhorar ou piorar. No trecho abaixo, Clara descreve o caminho de uma tomada de decisão.

"Acho que a primeira coisa é a intensidade da dor, o que ele relata. (...) A partir daí você vai ver: 'Bom, está doendo, se está doendo muito eu tenho que entrar com alguma coisa, mas o que que eu vou entrar pra ele?', aí vêm as outras coisas, como é que essa dor? o que que melhora? O que que piora? O que que você já usou? O que que você já fez? Uma coisa pra mim que é super importante, o que é que melhora essa dor? (...) quando você alonga melhora? Outros pioram" (Clara, anestesista, Clínica $\mathrm{H})$.

Entender as variações da dor é um processo que permite reconhecer o que Mário (anestesista, Clínica H) chamou de "pequenas conquistas" e Arthur (anestesista, Clínica H) de "pistas". A primeira frase que um doente com dor crônica diz ao chegar ao médico é " a dor não melhorou, Dr.”, “a dor continua, Dr.”. Trabalhar nas entrelinhas é aprender a valorizar o processo, aprender a reconhecer os ganhos, mesmo que parciais. Procurar incluir o doente no processo terapêutico, não pela obediência, mas pela receptividade e pela singularização. Este elemento admite que os protocolos pré-definidos sejam relativizados. As decisões do médico passarão pela intimidade, pela confiança, pela sensibilidade em perceber o que aquela pessoa poderá aceitar.
Tornam-se imprescindíveis garantir a permanência do doente no tratamento, a manutenção da relação médico-paciente e o retorno do doente ao serviço. Permanecer como terapeuta é estar no ponto certo entre a aproximação e o distanciamento e principalmente sustentar o processo terapêutico com o retorno do doente. Mário descreve este exercício da sustentação ao acompanhar uma jovem mulher com dificuldades familiares e em manter o tratamento.

"A minha maior missão com ela é que eu não perca a condição de terapeuta com relação a ela, que eu consiga que ela retorne, quer dizer, que não se sinta rejeitada ou desprezada por mim, que continue me procurando porque a gente vê que o resultado vem. Quando ela sai do tratamento por algum motivo, ela tem uma queda bastante grande (...) quando ela adere, ela melhora a qualidade de vida dela. (...) Então, eu tento manter esse vínculo" (Mário, anestesista, Clínica $\mathrm{H}$ ).

Sustentar este processo passa por acreditar no que o doente lhe traz, negociar o projeto terapêutico e monitorar os resultados.

\section{Para tratar o invisível é preciso crer - a prioridade do projeto terapêutico}

A ambigüidade entre crer e suspeitar, reconhecer a fala do doente como verdade, como ponto de partida e suspeitar dessa verdade, está presente no cotidiano clínico, nas discussões de caso, nos corredores e freqüentemente é traduzida como comportamento doloroso.

Diante da invisibilidade da dor, resta ao médico crer no que o doente diz. É um ponto de partida, "eu acredito no que o doente diz. Eu parto da premissa que o doente está falando a verdade para mim, embora eu saiba que ele não está (...) eu tenho que ter um ponto de partida, se ele diz que ele está tomando [remédios] (...) essa é a verdade do doente pra mim (...) eu preciso que exista uma corelação entre o que ele está falando e o que ele está melhorando" (Maria, neurologista, Clínica M).

Durante a formação, esta é uma exigência difícil de ser cumprida. Acreditar em algo tão subjetivo, superar a desconfiança e entender que o pilar do processo terapêutico é acreditar na dor do doente, é um aprendizado lento que é facilitado com a ajuda de alguém com mais experiência no tratamento da dor crônica. O diálogo entre Márcio (estagiário, Clínica M) e Dra. Maria (neurologista, Clínica M) oferece uma rica descrição deste processo: "Eu no começo do estágio, fiquei indignado com um paciente aqui. Eu disse, assim: 'Dra Maria, esse cara, eu não quero ver a cara dele mais. Esse cara é um farsante'. Ela disse: 'Calma meu filho, você está começando (...) e é 
assim mesmo, tem um ou outro gato pingado no seu consultório, vai ser assim (...) e você vai ter que levar no piano. Porque você não pode desacreditar do paciente, está entendendo?'. Foi a lição do dia. Daquele paciente eu aprendi isso" (Márcio, estagiário, Clínica M).

Márcio tenta uma explicação para esta premissa "sempre acredite na dor do paciente", considerando que ela permite sustentar a relação médico-paciente. Esta premissa assenta-se no reconhecimento de que a dor é apenas um dos elementos do sofrimento daquele sujeito e é preciso saber mais sobre o lugar que ocupa na vida do doente. Muitas vezes é somente aí que se poderá fazer alguma coisa.

A adesão ao tratamento dos doentes crônicos é um tema muito problematizado na literatura médica contemporânea e é reconhecida a dificuldade do uso contínuo de qualquer medicação. No caso da dor crônica, entretanto, observam-se peculiaridades. Não usar regularmente a medicação prescrita não indica, necessariamente, a não adesão ao tratamento como um todo, pode inclusive indicar a possibilidade deste doente manejar melhor seu próprio tratamento.

“...a gente sabe que o uso crônico de uma medicação, uma hora ele vai deixar de tomar (...) vai tomar um dia, no outro não (...) se não está tomando e não está vindo se queixar, tudo bem (...) em termos de dor, por exemplo, qual a conseqüência que ele vai ter na vida? (...) também tem um outro significado, eu posso ter dor e suportar melhor (...) será que ele modificou as crenças?..." (Maria, neurologista, Clínica M).

A mesma médica ressalta que este projeto terapêutico só é possível em equipe: “a equipe divide isso e o resultado é muito melhor (...) você não fica com essa sobrecarga da complexidade do quadro. Pode dividir a responsabilidade". Para um médico com mais de dez anos nesta especialidade é inevitável frustrar-se diante da permanência da dor e revelar esta frustração pode ajudar na relação com o doente.

“...então eu falo para meu paciente (...) você vai se frustrar. Dor crônica é crônica (...) e a gente vai se frustrar com você também quando não tem resultado (...) então dor frustra muito o profissional, eu acho isso um impacto muito forte" (Arthur, anestesista, Clínica H).

O projeto terapêutico para a dor crônica, portanto, assume como pressuposto a permanência da dor, investe no alívio e na reorganização do mundo-da-vida, mas não se compromete com a eliminação da dor. O reconhecimento desta permanência é, sem dúvida, o ponto de partida "dor crônica é crônica", "não vou curar a sua dor", são as afirmativas iniciais, para a introdução do projeto terapêutico. Estas assertivas confrontam- se inicialmente com as expectativas do doente e a modificação desta expectativa é o primeiro passo da terapêutica. A expectativa do médico também é posta em cheque.

Os objetivos terapêuticos vão girar em torno de retomar as atividades cotidianas, recuperar a função, sair do isolamento social, apesar da permanência da dor. Estes passam por deslocar a dor do centro da vida e colocá-la em uma margem conhecida e talvez controlável 27,28. Esta é a perspectiva terapêutica da reabilitação.

“Eu sempre espero que ele melhore da dor, mas não é isso que a gente verifica. Então quando vamos cair na real tem paciente que você melhora muito a dor e tem outros que não (...) mas ele melhora o desejo, o prazer de viver, outros melhoram a função de vida, quer dizer, ele estava lá jogado, não queria fazer mais nada e de repente ele volta a fazer, de repente através do tratamento. Então, é a reabilitação global do indivíduo, é o que eu quero" (Maria, neurologista, Clínica M).

Kotarba 27 propõe que o sucesso do gerenciamento da dor crônica passa por abordar muitos elementos da vida do doente, a dinâmica familiar, o comprometimento físico e psíquico, a inserção social e produtiva, mas que o foco dessa terapêutica deve ser a busca de sentido para a dor na vida, enquanto um elemento central para quebrar o ciclo vicioso da dor, utilizando-se para isso da dimensão religiosa, a participação social, a literatura, a troca de experiência com outros doentes. Esta proposição vai ao encontro do que Good ${ }^{11}$ e Good \& Good ${ }^{19}$ chamaram de modelo hermenêutico, capaz de a partir de uma compreensão do sentido do cuidado, da saúde e da cura, gerar modelos alternativos ao entendimento empiricista da doença para a prática clínica.

Durante as entrevistas e, principalmente, na observação em campo constata-se que estas estratégias nem sempre são usadas no cotidiano do atendimento. Para uma médica residente, recém-chegada, esta valorização da escuta nem sempre é fácil de conciliar com as demandas do serviço: "eu saio daqui sugada, quando eu vejo que esta pessoa precisa falar e eu tenho ainda tantas consultas para atender" (Paula, residente, Clínica H). No entanto, é consenso entre estes terapeutas que é preciso escutar: se o doente não falar o que precisa durante a consulta, nada que for proposto será seguido.

\section{Discussão}

A ênfase na terapêutica orientada para o monitoramento e gerenciamento da dor a partir do seu "entorno", tendo como metas o deslocamento da dor do centro da vida e a reconstrução do mun- 
do-da-vida de quem sofre são características do modus operandi do trabalho médico na Clínica de Dor 10,12,13,27,28. Para Isabelle Bazanger 10 as características da dor crônica vão modificar o trabalho médico e atuar centralmente na experiência da doença, levando à mudança da posição do doente no processo terapêutico, deixando de ser passivo para fazer parte da divisão do trabalho médico. Cabe a este médico empreender um processo de negociação implícito ou explícito no sentido de envolver o doente enquanto um gerente de seu próprio sofrimento, passando o médico a ter um papel de monitor e legitimador da dor, buscando retirá-la de sua subjetividade absoluta, reconhecendo seus impactos na vida do doente.

Este movimento incita o médico clínico a romper com alguns dos cânones da biomedicina - a objetividade e o distanciamento - aproximando-o da clínica enquanto prática eminentemente interpretativa e hermenêutica. $\mathrm{O}$ que requer aproximação e respeito à singularidade $8,20,29$. A equipe na clínica de dor pode ser vista como um "sistema terapêutico complexo" 23 que contempla o trabalho do corpo, da mente, do movimento, do relaxamento. Apesar de congregar várias práticas terapêuticas e diferentes profissionais de saúde, a clínica de dor mantém o médico como o gerente do sistema terapêutico e a biomedicina como racionalidade médica hegemônica 20 .

Constata-se que diante da invisibilidade é preciso crer, mas este pressuposto inicialmente parece paradoxal e incompatível com a racionalidade biomédica. O sujeito doente precisa falar, precisa ser escutado e ser clínico de dor passa por aprender a escutar. Ao lado do que Good 11 chamou de princípios formativos da biomedicina "o olhar, o escrever e o falar", é possível sugerir que a Clínica de Dor requer a valorização do "escutar, compreender e negociar" se não como princípios formativos, mas como recursos mobilizados pela prática clínica para a viabilização do encontro clínico.
A inevitabilidade da dor crônica 28 , ou seja, o seu reconhecimento enquanto uma patologia de caráter crônico é um ponto de conflito entre médico e doente. Os centros multidisciplinares de dor organizam-se em torno de uma ideologia orientada para a adaptabilidade à dor e o reconhecimento da influência de atitudes e comportamentos na expressão da dor. Este pressuposto admite que determinadas atitudes do doente possam indicar uma disposição à redução ou eliminação da dor, como também, no outro extremo, poderá responsabilizar o doente por sua dor 12,14 .

Na Clínica de Dor a terapêutica caracteriza-se pela singularidade. A valorização da perspectiva compreensiva exige lidar com um repertório de modelos interpretativos mais amplo: bioquímico, genético, ambiental, psico-dinâmico, familiar interacionista, farmacológico 11,19. Na conjunção destes modelos, onde a causa perde em importância para o processo de adoecimento e o diagnóstico para a terapêutica, constrói-se a viabilidade para o exercício de um modelo clínico híbrido - hermenêutico e biomédico - movimentando-se entre estes dois pólos, orientado pela experiência como terapeuta e pela disponibilidade do doente.

Concordando com Sayd 30 (p. 155), o médico no exercício da clínica confronta-se com seu duplo papel social: "de ser um representante de um corpo de normas e conhecimentos", muitas vezes rígido e comprometido com o controle social, mas, ao mesmo tempo, vê-se "submetido a regras mais antigas (...) enquanto um terapeuta frente a um doente, um caso, uma situação humana". É neste lugar que o médico situa-se como o gerente do projeto terapêutico da dor crônica: um mediador, aprendendo a lidar com as incertezas do próprio trabalho e com as dificuldades de ter que reconhecer que "às vezes sabe e às vezes não sabe" 26 (p. 185). 


\section{Resumo}

Este trabalho teve como objetivo compreender os sentidos da dor crônica no discurso e na prática clínica de médicos nos espaços terapêuticos de duas Clínicas de Dor, situadas em hospitais-universitários de Salvador (Bahia) e São Paulo, Brasil. Foi realizado um estudo etnográfico a partir de observação participante e entrevistas semi-estruturadas com médicos (terapeutas e coordenadores de serviço). A análise dos dados foi inspirada nos modelos clínicos desenvolvido por Byron Good e o projeto de racionalidades médicas, formulado por Madel Luz. O reconhecimento da dor crônica pela biomedicina enquanto doença e não como sintoma, sua invisibilidade ao olhar médico, sua incomunicabilidade e inevitabilidade foram os sentidos emergentes neste trabalho. A valorização do encontro humano na clínica, o exercício da compreensão em contraposição à suspeição (distanciamento) e a construção de projetos terapêuticos negociados e sustentáveis a longo tempo foram apontados pelos informantes como necessários no trabalho com dor crônica.

Dor; Clínicas de Dor; Condutas na Prática dos Médi$\cos$

\section{Colaboradores}

M. A. G. Lima foi a idealizadora do projeto de pesquisa e responsável por sua coordenação e execução. L. A. B. Trad colaborou em todas as etapas deste trabalho desde a formatação e condução da pesquisa até a elaboração deste artigo.

\section{Agradecimentos}

Este trabalho teve a colaboração da Coordenação de Aperfeiçoamento de Pessoal de Nível Superior/Conselho Nacional de Desenvolvimento Científico e Tecnológico (CAPES/CNPq) e Fundação de Amparo à Pesquisa do Estado da Bahia (FAPESB) na forma de bolsa de doutorado.

Nossos agradecimentos especiais a Dr. Durval Kraychete, coordenador da Clínica de Dor do Hospital Professor Edgar Santos, Faculdade de Medicina, Universidade Federal da Bahia e a Dr. Manoel Jacobsen, coordenador do Centro Multidisciplinar de Dor, Faculdade de Medicina, Universidade de São Paulo, pela importante contribuição para a viabilização deste trabalho.

\section{Referências}

1. Eliot AM, Smith BH, Penny KI, Smith WC, Chambers WA. The epidemiology of chronic pain in the community. Lancet 1999; 354:1248-52.

2. Blyth FM, March LM, Brnabic AJ, Jorm LR, Williamson M, Cousins MJ. Chronic pain in Australia: a prevalence study. Pain 2001; 89:127-34.

3. Cohen MJM, Campbell JN, editors. Pain treatment centers at a crossroads: a practical and conceptual reappraisal. Seattle: IASP Press; 1996.

4. Jackson JE. Chronic pain and the tension between the body as subject and object. In: Csordas TJ, editor. Embodiment and experience: the existential ground of culture and self. Cambridge: Cambridge University Press; 1994. p. 201-28.

5. Morris D. La cultura del dolor. Santiago de Chile: Editora Andrés Bello; 1996.

6. Melzack R, Wall PD. O desafio da dor. Lisboa: Fundação Calouste Gulbenkian; 1982.

7. Csordas TJ, Clark JA. Ends of the line: diversity among chronic pain centers. Soc Sci Med 1992; 34:383-93.

8. Kleinman A, Brodwin PE, Good BJ, Good MJD, editors. Pain as human experience. Berkeley: University of California Press; 1994.
9. Pimenta CAM. Atitudes de doentes com dor crônica frente à dor [Tese de Doutorado]. São Paulo: Escola de Enfermagem, Universidade de São Paulo; 1999.

10. Baszanger I. Pain: its experience and treatments. Soc Sci Med 1989; 29:425-34.

11. Good B. Medicine, rationality, and experience: an anthropological perspective. Cambridge: Cambridge University Press; 1994.

12. Jackson JE. "Camp pain": talking with chronic pain patients. Pennsylvania: University of Pennsylvania Press; 2000.

13. Kirmayer LJ. On cultural mediation of pain. In: Coakley S, Shelemay K, editors. Pain and its transformations. Cambridge: Harvard University Press; in press.

14. Kirmayer LJ. Mind and body as metaphors: hidden values in biomedicine. In: Lock M, Gordon DR, editors. Biomedicine examined. Holland: Kluwer Academic Publishers; 1988. p. 57-93.

15. Becker HS. Métodos de pesquisa em ciências sociais. São Paulo: Editora Hucitec; 1994. 
16. Turk DC. Efficacy of multidisciplinary pain centers in the treatment of chronic pain. In: Cohen MJM, Campbell JN, editors. Pain treatment centers at a crossroads: a practical and conceptual reappraisal, progress in pain research and management. Seattle: IASP Press; 1996. p. 257-73.

17. Lippel K. Therapeutic and anti-therapeutic consequences of workers' compensation. Int J Law Psychiatry 1999; 22:521-46.

18. Oliveira RC. O trabalho do antropólogo: olhar, ouvir, escrever. Brasília: Editora Paralelo 15; 1998.

19. Good B, Good MJD. The meaning of symptoms a cultural hermeneutic model for clinical practice. In: Eisenberg L, Kleinman A, editors. The relevance of social science for medicine. Dordrecht: Reidel Publishing Company; 1980. p. 165-96.

20. Camargo Junior KR. Biomedicina, saber e ciência: uma abordagem crítica. São Paulo: Editora Hucitec; 2003.

21. Foucault M. O nascimento da clínica. Rio de Janeiro: Editora Forense Universitária; 1977.

22. Canguilhem G. O normal e o patológico. Rio de Janeiro: Editora Forense Universitária; 1982.
23. Lima MAG. Clínica da dor: sentidos e práticas no cotidiano dos espaços terapêuticos [Tese de Doutorado]. Salvador: Instituto de Saúde Coletiva, Universidade Federal da Bahia; 2005.

24. Scarry E. The body in pain: the making and unmaking of the world. New York: Oxford University Press; 1985.

25. Good B. Medicine, rationality, and experience: an anthropological perspective. Cambridge: Cambridge University Press; 1994.

26. Clavreu J. A ordem médica: poder e impotência do discurso médico. São Paulo: Editora Brasiliense; 1983.

27. Kotarba JA. Chronic pain center: a study of voluntary client compliance and entrepreneuship. Am Behav Sci 1981; 24:786-800.

28. Hilbert RA. The acultural dimensions of chronic pain: flawed reality construction and the problem of meaning. Soc Probl 1984; 31:365-78.

29. Lock M, Gordon D. Biomedicine examined. Dordrecht: Kluwer Academic Publishers; 1988.

30. Sayd JD. Mediar, medicar, remediar: aspectos da terapêutica na medicina ocidental. Rio de Janeiro: EdUerj; 1998.

Recebido em 16/Out/2006

Versão final reapresentada em 12/Fev/2007

Aprovado em 01/Mar/2007 